\title{
Adsorption and Kinetic Study of Methylene Blue dye on New Surface Derived from Copolymer (Melamine - Formaldehyde - Para- methyl Anisole)
}

\author{
Waeel M. Hamud*
}

Received 2, December, 2013

Accepted 8, March, 2014

\begin{abstract}
:
A new copolymer (MFA) was prepared from condensation of melamine (M) with pmethyl - anisole (A) in the presence of condensation agent like $37 \%(\mathrm{w} / \mathrm{v})$ of formaldehyde. The new copolymer was characterized by elemental, IR and HNMR spectra. The chelating ion-exchange property of this polymer was studied for methylene blue dye in aqueous solution in 100-200ppm concentrations. The adsorption study was carried out over a wide range of $\mathrm{pH}$, shaking time and in media of various kinetic parameters models. Thermal parameters like enthalpy, entropy and Gibbs free energy of adsorption process of methylene blue on surface of MFA resin were determined on the basis of kinetic parameters at different temperatures. To describe the equilibrium of adsorption, the Langmuir, Freundlich and Temkin isotherms were used. The Langmuir isotherm correlation $\left(\mathrm{R}^{2}=0.987\right)$ was the best fitted for experimental data with maximum adsorption capacity of $200 \mathrm{ppm}$. A higher correlation value of the kinetic's model was observed close to pseudo first order, second order and Temkin kinetic models values of correlation $\mathrm{R}^{2}$ lie in the range (0.983-0.987) in comparing to other kinetic models.
\end{abstract}

\section{Key words: Adsorption, methylene blue, kinetics \& equilibrium.}

\section{Introduction:}

The synthesized copolymer showing versatile applications and properties attracted the attention of scientists and introduce the recent innovations in the polymer chemistry. These copolymers can be used as high energy material [1], ion-exchanger [2], semiconductors [3], antioxidants [4], fire proofing agent [5], optical storage data [6], binders [7], molding materials, [8].The kinetic properties of copolymer have gained sufficient ground in recent years. The work on thermal and kinetic studies of interactions of copolymers with toxic organic materials have been carrying out extensively due to their wide applications in areas such as chemically modified electrodes, sensors etc $[9,10] . .$, C.H.Weng and Co-
Workers [11] have been adopting the electrical conductivity of salicylic acidbiuret/dithio- oxamide/dithiobiuret trioxane polymer resins and their kinetic study. Ion-exchange technique can remove traces of azo dyes impurities from water/process liquors and gives out a product of ultra pure quality in a simple efficient and techno-economically viable manner. Various Hydroxybenzoic acidformaldehyde and 4hydroxyacetophenone-biuret-

formaldehyde copolymers have been reported and found to be used as ionexchangers $[12,13]$.Hence the adsorption, kinetic and equilibrium properties of the newly copolymer

*Chemistry Department - College of Science - Al- Mustansiriya University Baghdad - Iraq 
were also reported for specific methylene blue dye.<smiles>CN(C)c1ccc2nc3ccc(N(C)C)cc3[s+]c2c1</smiles>

Fig. (1): chemical structure of methylene blue dye

\section{Materials and Methods:}

\section{Starting materials:}

The chemicals (starting materials) used in the synthesis were of analar or chemically pure grade, and wherever necessary the purity was tested and confirmed by TLC.

\section{Synthesis of MFA copolymer:}

The copolymer MFA was prepared according to the modified method published in literature [13] involving the condensing p-methoxy-toluene $(3.77 \mathrm{~g}, 0.2 \mathrm{~mol})$ and melamine $(1.26$ $\mathrm{g}, 0.1 \mathrm{~mol})$ with $37 \%$ formaldehyde $(11.1 \mathrm{ml}, 0.3 \mathrm{~mol})$ in a mol ratio of $2: 1: 3$ in the presence of $125 \mathrm{ml} 1 \mathrm{M} \mathrm{HCl}$ as a catalyst at $125^{\circ} \mathrm{C} \pm 2{ }^{\circ} \mathrm{C}$ for $6 \mathrm{hr}$ in an oil bath with occasional shaking to ensure through mixing. The separated polymer was washed with hot water and methanol to remove unreacted starting materials and acid monomers. The properly washed resin was dried, powdered and then extracted with petroleum ether to remove new copolymer (soluble in petroleum ether) .The copolymer was further purified by dissolving in $5 \%(\mathrm{w} / \mathrm{v})$ of aqueous $\mathrm{NaOH}$, and repreciption of the copolymer was done by addition of cold concentrated $\mathrm{HCl}$. The process of reprecipitation was repeated twice. The copolymer sample MFA, thus obtained was filtered, washed several times with hot water, dried in air, powdered and kept in vacuum desiccators over silica gel. The yield of the polymer resin was found to be 90\%. The physical properties of new resin have bases on the surface area $240 \mathrm{~m}^{2} / \mathrm{gm}$, length $=50$ micro-metre, thermal conductivity $=80-100 \mathrm{w} / \mathrm{mV}$ and diameter $=500-900 \mathrm{~nm}$.

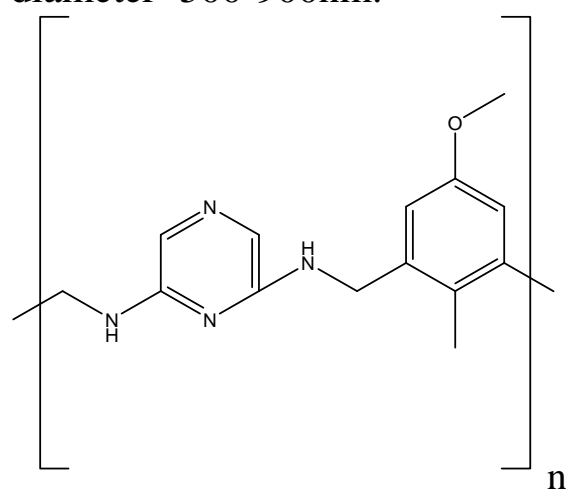

Fig. (2): structure of copolymer (melamine formaldehyde p-methylanisole)

\section{Batch Adsorption Experiments:}

In order to contact between adsorbent MFA and dye solution, all tests were conducted in a closed Erlenmeyer flasks with $100 \mathrm{~mL}$ capacity as a batch system. Different doses of MFA tere polymer were applied by adding $(0.15$, 0.25 , and $0.35 \mathrm{gm}$ ) of adsorbent per (100 mL )of dye solution. Furthermore, the $\mathrm{pH}$ was adjusted to the desired value with( $1 \mathrm{M}) \mathrm{HCl}$ and $\mathrm{NaOH}$ (Merck, Germany). In this study, various parameters such as contact time ranges from (20-200 minutes), $\mathrm{pH}$ 3 to 9 , adsorbent dosage $(0.2,0.4,0.6$ $\mathrm{g} / \mathrm{L})$, initial dye concentrations (50, $100,150$, and $200 \mathrm{mg} / \mathrm{lit})$ were investigated in different experiments. In all experiments, the temperature was kept constant (298K). For better mixing, the Erlenmeyer flasks which contain 100-200 mg/lit of dye solution were placed in the illuminated refrigerated incubator shaker (Inn ova 4340, USA) and were agitated at (150 $\mathrm{rpm})$. At the end of equilibrium time the suspensions were centrifuged for (30 min). at (3000 rpm) and then the supernatant of suspension was filtered 
using a $(0.60 \mu \mathrm{m})$ Millipore filter. The final dye concentrations (methyenel blue) were evaluated by UV-visible spectrophotometer (Shimadzu 670spectrometer) at maximum wavelength $(415-650 \mathrm{~nm})$. After taking these measurements, the concentrations of residual dye were determined by calibration curves. Removal efficiency, adsorption capacity $(\% \mathrm{E})$ was calculate using mathematical equations of adsorption.

\section{Results and Discussion:}

1. Characterization of polymer resin:

The elemental analysis $(\mathrm{CHN})$, degree of polymerization $\mathrm{Dp}$, and the linearity of viscosity according to Taun- Fuoss viscometer at different concentrations ranging from $(0.05$ to $1.02 \%$ ) of polymer in DMSO at (298
$\mathrm{K}^{\circ}$ ) was evaluated by relevant plots of Huggin's equation (1) [14] .

$\mu_{\mathrm{sp}} / \mathrm{c}=[\mu]+\mathrm{k}_{1}[\mu]^{2} \mathrm{c}$

$\ln \mu_{\mathrm{r}} / \mathrm{c}=[\mu]+\mathrm{k}_{2}[\mu]^{2} \mathrm{c}$

where $\mathrm{c}=$ concentration in $\mathrm{gm} / 100 \mathrm{ml}$

$\mu_{\mathrm{r}}=$ ratio of polymer viscosity to viscosity of pure solvent (DMSO)

$[\mu]=$ intrinsic viscosity which characteristic parameter of a polymer

The values of carbon, hydrogen and nitrogen parameters performed with micro-elemental analysis on PerkinElmer 2400 analyzer were acceptable with proposed repeated unit of $\left(\mathrm{C}_{23} \mathrm{H}_{26}\right.$ $\mathrm{N}_{6} \mathrm{O}_{4}$ ) with physical properties $\mathrm{D}_{\mathrm{p}^{-}}=$ $15.5, \mathrm{Mn}=688.9 \mathrm{~g} / \mathrm{mol}$ and intrinsic viscosity of the value $0.895 \mathrm{dl} / \mathrm{g}$.

Table (1): elemental analysis ,viscosity and other physical properties.

\begin{tabular}{|c|c|c|c|c|c|}
\hline \multirow{4}{*}{$\mathrm{C}_{23} \mathrm{H}_{26} \mathrm{~N}_{6} \mathrm{O}_{4}$} & $\begin{array}{c}\mathrm{CHN} \\
(61.22)^{*}\end{array}$ & $\begin{array}{c}\text { Surface } \\
\text { area } \mathrm{m}^{2} / \mathrm{gm}\end{array}$ & Length $\mu \mathrm{m}$ & $\begin{array}{c}\text { Thermal } \\
\text { conductivity } \mathrm{w} / \mathrm{v}\end{array}$ & Diameter $\mu \mathrm{m}$ \\
\cline { 2 - 3 }$(450 \mathrm{~g} / \mathrm{mole})$ & $\begin{array}{c}\mathrm{C} \% 6.221 \\
(6.51)^{*}\end{array}$ & & & & \\
\cline { 2 - 3 } & $\begin{array}{c}\mathrm{N} \% 19.95 \\
(20.11)^{*}\end{array}$ & & 50 & $80-100$ & $50-90$ \\
\hline
\end{tabular}

$*$ = values found by elemental analysis

\section{2. ${ }^{1}$ H NMR Spectroscopy:}

The proton NMR spectrum of the copolymer (MFA) was scanned in DMSO-d6 on 300 MHZ- Brunker Ultra shield NMR spectrometer at AlYarmok University (Jordan) using TMS (tetra methyl silane ) as internal solvent and the absorptions of proton $\left({ }^{1} \mathrm{H}\right)$ resonances were measured as chemical shift $(\delta)$ in part per million (ppm ) units from (0-14) ppm range, figure (3).

The absorption of proton NMR of MFA copolymer in DMSO-d6 showed singlet chemical shifts at 2.50-2.51, 3.61 and $5.75 \mathrm{ppm}$, which were belonged to resonance at DMSO solvent, $\left(\mathrm{CH}_{2}-\mathrm{N}\right)$ and $\left(-\mathrm{OCH}_{3}\right)$ protons respectively $[15,16]$. While the deshielded absorption at 6.65-6.76 and 7.56-7.83 ppm may attributed to aromatic (A-H) and $(\mathrm{C}-\mathrm{H})$ of melamine moiety respectively. The data obtained from ${ }^{1} \mathrm{H}$ NMR spectrum confirm the proposed structure of the newly copolymer. 


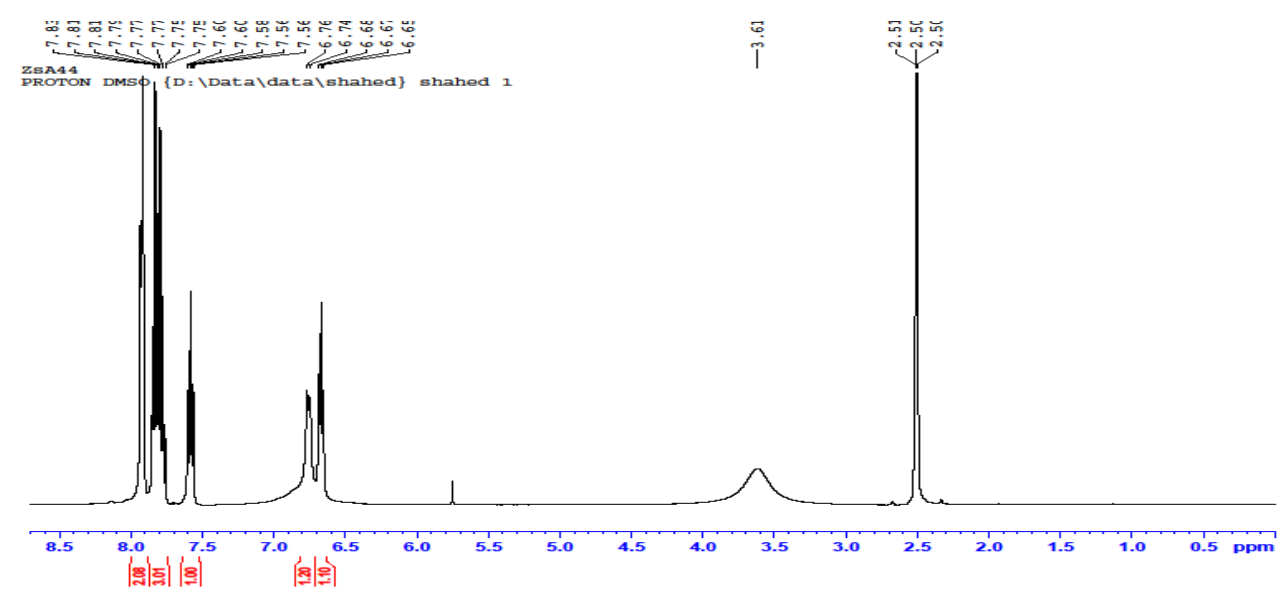

Fig. (3): ${ }^{1} \mathrm{H}$ NMR spectrum of MFA copolymer in DMSO-d6 solution.

\section{Infra-red Spectrum:}

Figure (4) shows the scanning of FTIR spectrum for thin film of MFA. A broad band appeared in the region $3500 \mathrm{~cm}^{-1}$ of - NH- related to ring of melamine, where as the absorptions as medium band at $3377-3282 \mathrm{~cm}^{-1}$ may be assigned to $-\mathrm{CH}_{2}-\mathrm{NH}$ polymerized as chain to p-methyl-anisole. The band obtained as sharp and medium intensities at 3100,2962 and $1500-$ $1600 \mathrm{~cm}^{-1}$, may suggest the presence of methylene bridges of formalin starting materials, melamine ring $\mathrm{C}=\mathrm{N}$ and $\mathrm{C}=\mathrm{C}$ of $\mathrm{p}$-methoxy toluene moiety respectively [17] . A sharp strong peak at $850-590 \mathrm{~cm}^{-1}$ may be due to-NHdeformation out of plane of secondary amine $[17,18]$.

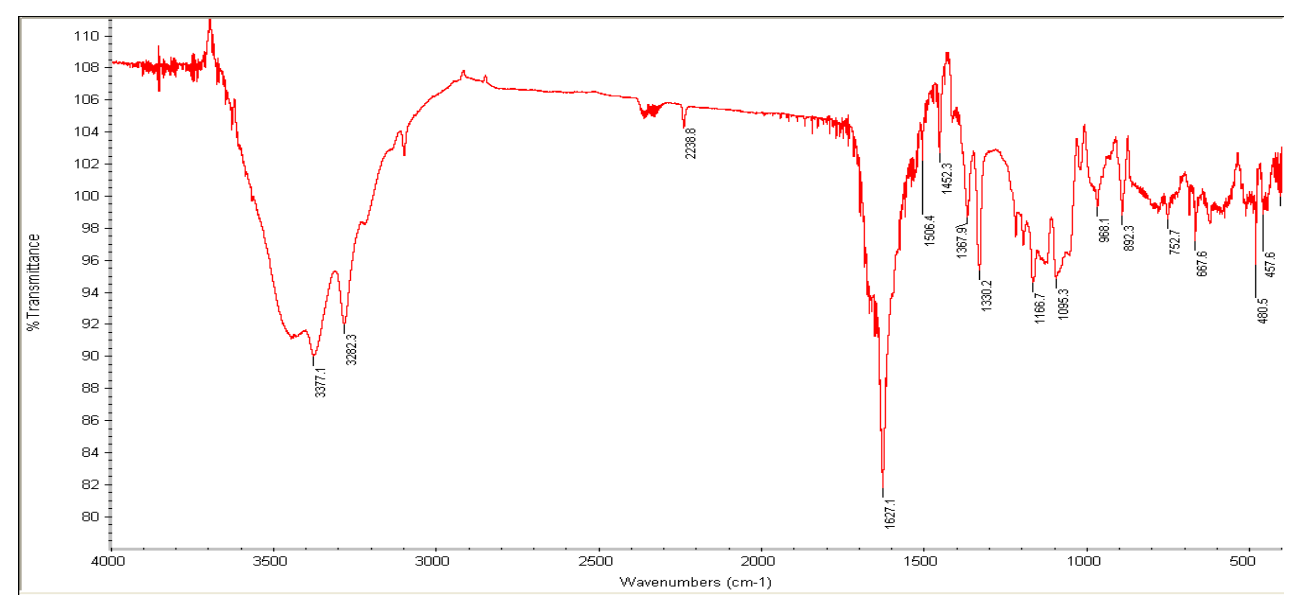

Fig. (4): IR spectrum of MB dye in $\mathrm{KBr}$ disc

\section{The Effect of contact time:}

The effect of contact time on the removal of methylene blue dye was studied and shown in figure (5). A rather fast uptake occurs during the first 50-100 minutes of adsorption process, followed by a slower stage as the adsorbed amount of dye reaches its equilibrium value. The equilibrium value. The equilibrium was found to be nearly 150 minutes when the maximum dye (MB) adsorption capacity was reached [19]. 


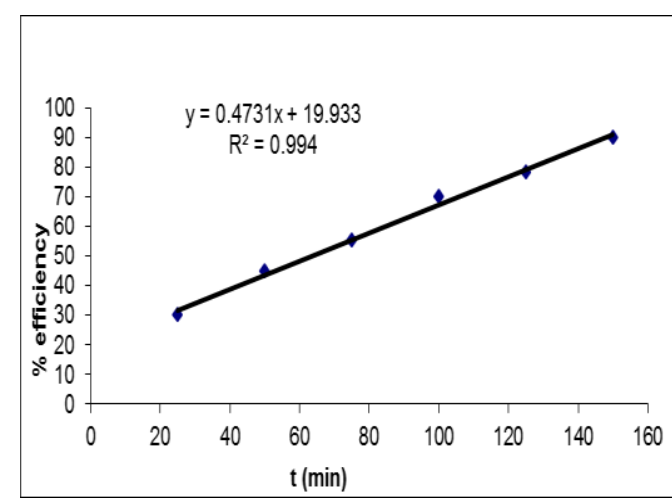

Fig. (5): Effect of time contact on \% efficiency of M.B. (100ppm)

\section{The Effect of $\mathrm{PH}$ adsorption of $\mathrm{MB}$ on MFA copolymer:}

The PH of the solution is one of the most important parameter to effect the adsorption this illustrates the effect of $\mathrm{PH}$ of the solution on the percents removal of methylene blue dye, which provides good evidence for the increasing the percents of efficiency with the lowering of the acidity of solution until reaches the plateau values at $\mathrm{PH} \sim 6.5$, this is investigating the saturation of resin surface functional groups $-\mathrm{NH}_{2}-\mathrm{C}=\mathrm{N}$ with $\mathrm{H}^{+}$ion at $\mathrm{PH}(2-5)$, and at $\mathrm{PH}$ $>7.0$ effects the ionization of methylene blue dye, since it involves protic and inprotic groups[19, 20].

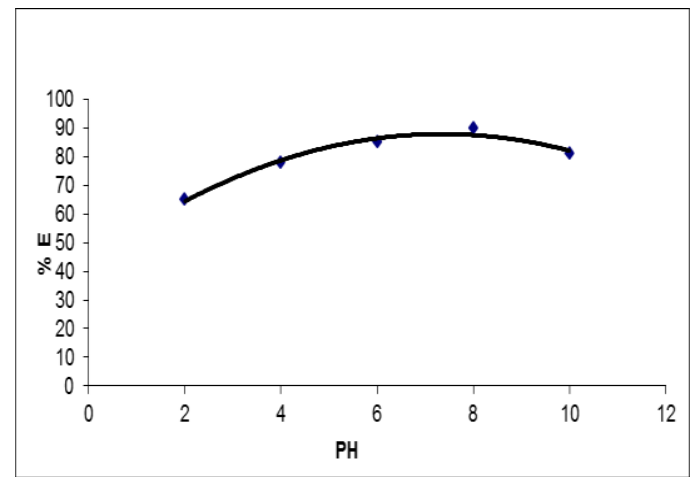

Fig. (6): Effect of $\mathrm{PH} \%$ removal adsorption of MB on MFA copolymer

\section{Adsorption Isotherm:}

In this study, various isotherms models such as Langmuir, Freundlich and Temkin were studied to describe the equilibrium characteristic of adsorption. Isotherm is a relationship between the equilibrium amount of methylene blue dye absorbed newly copolymer (melamine formaldehyde $\mathrm{p}$ methoxy toluene ) surface and residual concentration of dye in solution. Figure (7) illustrates Langmuir isotherm plot. For experimental data $\mathrm{R}^{2}$ was determined from straight line found to be 0.9872, this one supports the heterogeneous process or surface of MFA copolymer. Further than Freundlich isotherm [21, 22] in figure (8) showed the linearly with $\mathrm{R}^{2}=$ 0.9809 which investigate the high efficiency of functional sites to interest with methylene blue dye like $\mathrm{C}=\mathrm{N}$, $\mathrm{OH} \& \mathrm{C}-\mathrm{S}$ groups, where $\mathrm{n}=1500.9$ sites.

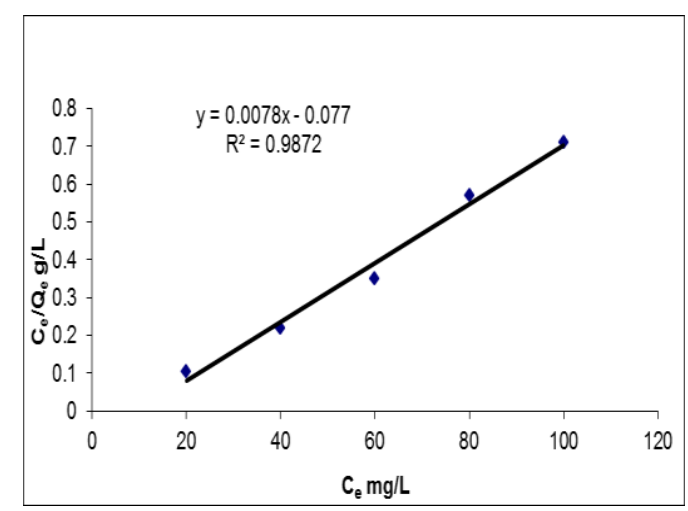

Fig. (7): Langmuir adsorption isotherm of $200 \mathrm{ppm}$ at $298 \mathrm{~K}$ on MFA surface

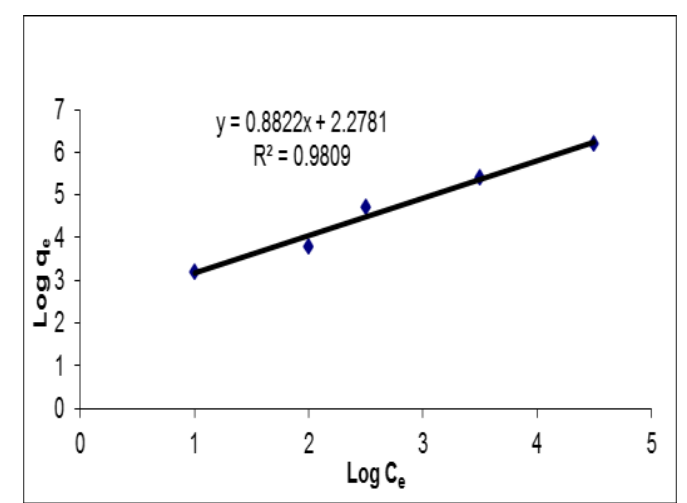

Fig. (8): Freundlich adsorption isotherm on MFA surface at 298K

In contrast with figure (9), Temkin model kinetic isotherm, the slope of 
formal line from plotting $\mathrm{I}$ is equal to 21.232 which confirms the good distribution of methylene blue molecules in the vacuities of surface of new copolymer, as well as the correlation of $\mathrm{R}^{2}=0.9578$, it is less the Langmuir and Freundlich models , leads to optimization of conditions like contact time, structure of methylene blue dye, temperature, regulation of solution , and PH of solution[20,23] .

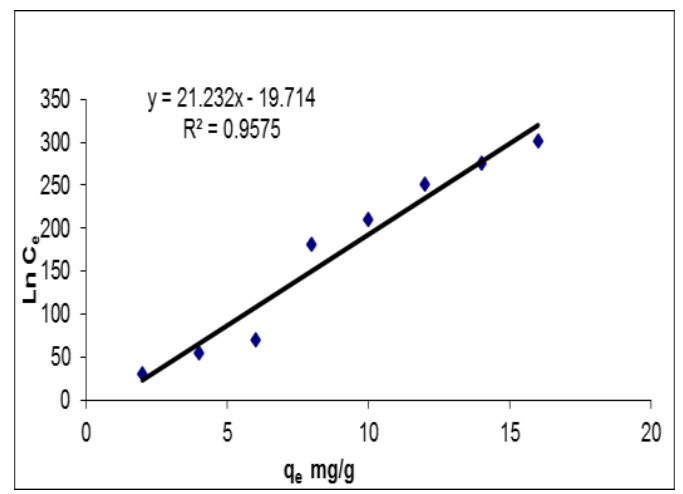

Fig. (9): Kinetic of Temkin isotherm of MB adsorption on MFA surface at 298K

The best time for contacting the sorbent (methylene blue) on the surface of MFA was 125 minutes, figure (5), at $\mathrm{PH}=6.5$ and $298 \mathrm{~K}$.

The effect of Hydronium concentrations $\left[\mathrm{H}_{3} \mathrm{O}^{+}\right]$on the adsorption process is shown in figure (6) where the $\mathrm{PH}=6.5$ it is optimum for interact of nitrogen groups of new resin with functional groups of sorbent [23] .

The adsorption isotherms Langmuir, figure (7) showed the linearity of adsorption models which involves the heterogeneous process at optimum conditions of $\mathrm{PH}$ in high concentration of methylene blue solution.

$\mathrm{Ce} / \mathrm{q}_{\mathrm{e}}=1 / \mathrm{Q} \cdot \mathrm{K}_{\mathrm{L}}+\mathrm{C}_{\mathrm{e}} / \mathrm{Q}$ 。

The plotting according to Freundlich isotherm model investigate the homogenous linearly of adsorbent with sorbent with $\mathrm{R}^{2}=0.988$ figure (7) that is very close to survey results [24]. $\log \mathrm{q}_{\mathrm{e}}=\log \mathrm{k}_{\mathrm{f}}+1 / \mathrm{n} \log \mathrm{C}_{\mathrm{e}}$

While for Temkin model of kinetic adsorption was shown in equation (4) and [25], which was investigated in literature of O.Hamdaoui and Coworkers.

$\mathrm{q}_{\mathrm{e}}=\mathrm{B}_{1} \operatorname{lnk}_{1}+\mathrm{B}_{1} \ln _{\mathrm{e}}$

\section{Kinetic Study:}

In order to investigate the capacity of dye mass interaction on surface of new copolymer MFA, kinetics adsorption was evaluated. The analysis of the isotherm data is important to develop an equation which accurately represents the results and could be used for design purpose [25, 26]. Therefore in this work the pseudo $-1^{\text {st }}$ and pseudo $2^{\text {nd }}$ order reactions kinetics for (100- $200 \mathrm{mg} / \mathrm{lit}$ ) of dye solution (in D.W) studied by following the changes of UV-Visible spectra (figure 10) at $(\chi=450,650 \mathrm{~nm})$ respectively, and these models are such as pseudo- first order: $\log \left(\mathrm{q}_{\mathrm{e}}-\mathrm{q}_{\mathrm{t}}\right)=\log \left(\mathrm{q}_{\mathrm{e}}\right)-\mathrm{k}_{1} / 2.303 . \mathrm{t}$---- (5)

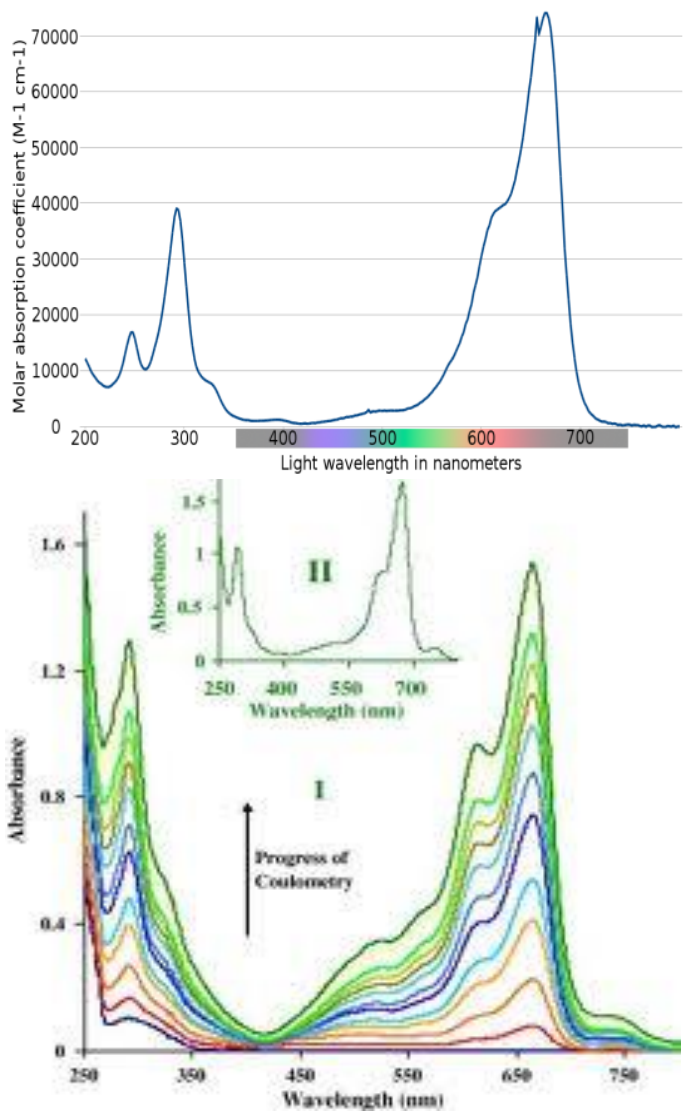

Fig. (10): Variation of UV-Visible spectra of MB in D.W before and after adsorption on MFA. 
The results obtained in the figure (11) investigate the straight line with $\left(\mathrm{k}_{1}\right.$ $=0.0214179 \mathrm{~min}^{-1}$ ) which support the effect of other factors besides the concentrations of $\mathrm{MB}$ on reaction of adsorption [25, 26].

In contract, figure (12) reveals the linearity of pseudo $2^{\text {nd }}$ order reaction with correlation factor $\mathrm{R}^{2}=0.9783$, slope $=0.0167$, according to equation (6) :

$1 / \mathrm{q}_{\mathrm{t}}=1 / \mathrm{n}+1 / \mathrm{q}_{\mathrm{e}} \cdot \mathrm{t}$

$\mathrm{q}_{\mathrm{e}}=59.880 \mathrm{mg} / \mathrm{lit}$ which reveals the high efficiency of adsorbed amount of MB dye on new copolymer, therefore, the structure and amount dose of copolymer, should be considered to obey to pseudo- $2^{\text {nd }}$ order kinetic adsorption [27].

Table (2): Kinetic details of MB adsorption of MFA copolymer.

\begin{tabular}{|c|c|c|c|}
\hline $\begin{array}{c}\text { Kinetic } \\
\text { models }\end{array}$ & Parameter & $1^{\text {st }}$ order & $2^{\text {nd }}$ order \\
\hline & $\mathrm{R}^{2}$ & 0.987 & 0.973 \\
\cline { 2 - 4 } & $\mathrm{q}_{\mathrm{e}}$ & 35.77 & 59.80 \\
\cline { 2 - 4 } $\begin{array}{c}100-200 \\
\mathrm{ppm}\end{array}$ & $\mathrm{K}_{1}$ & $\begin{array}{c}0.02141 \\
\mathrm{~min}^{-1}\end{array}$ & \\
\cline { 2 - 4 } & $\mathrm{K}_{2}$ & $\begin{array}{c}59.80 \\
\mathrm{~min}^{-1} \mathrm{M}^{-1}\end{array}$ \\
\hline
\end{tabular}

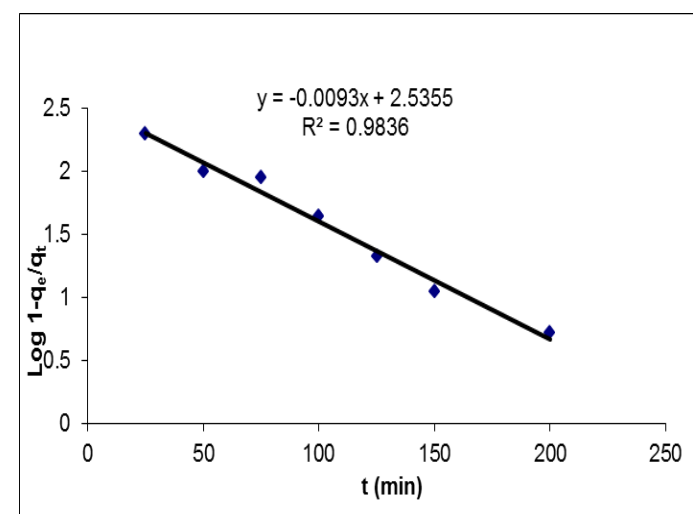

Fig. (11): First order kinetic of MB adsorption on MFA copolymer

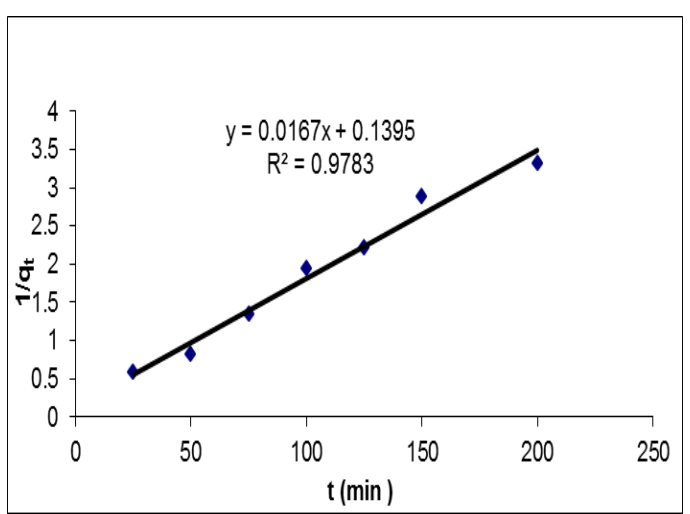

Fig. (12): Second order kinetic plotting for MB adsorption on MFA copolymer

The thermodynamic study to evaluate $\Delta \mathrm{H}, \Delta \mathrm{S}$ and $\Delta \mathrm{G}$ values of the adsorption of MB dye on MFA resin was adopted and shown in figure (13a, $13 b, 13 c)$.

$\Delta \mathrm{H}$ Results from slope of Vant-Hoff' equation $=18.95 \mathrm{Kcal} / \mathrm{mole}, \Delta \mathrm{S}=$ $56.60 \mathrm{Kcal} / \mathrm{mole}$ while $\Delta \mathrm{G}=-5364.3$ $\mathrm{Kcal} / \mathrm{mole}$, these results indicate the endothermic process with spontaneously, due to presence functional groups presents on both dye $\mathrm{MB}$ and new copolymer [28,29].

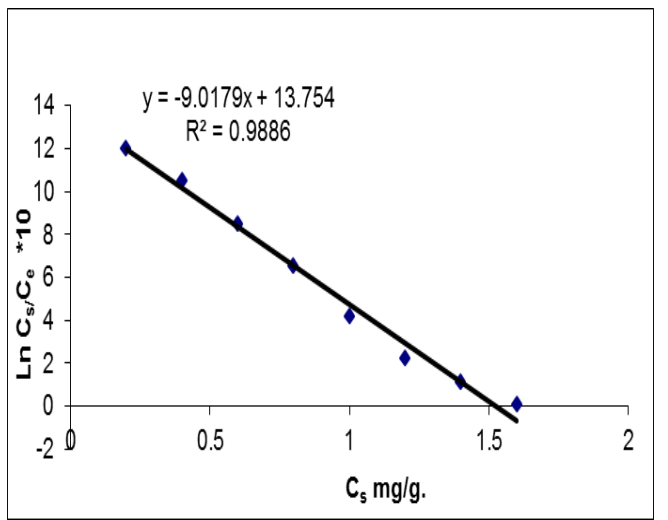

Fig. (13a): Vant Hoof's plotting of MB dye adsorption (200ppm) on MFA copolymer at $298 \mathrm{~K}$ 


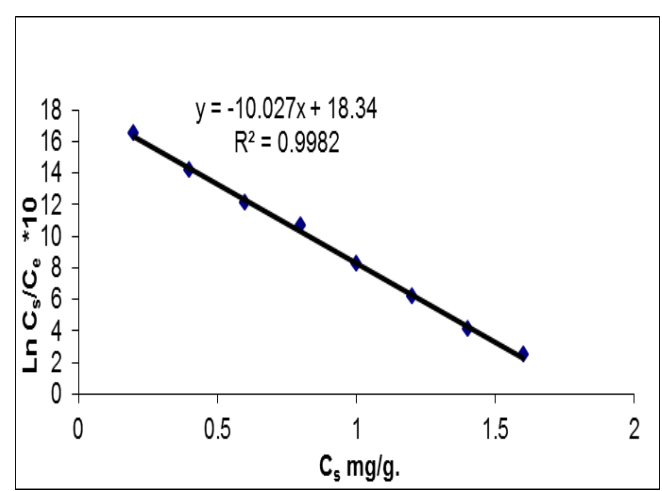

Fig. (13b): Vant Hoof's plotting of MB dye adsorption (200ppm) on MFA copolymer at $308 \mathrm{~K}$

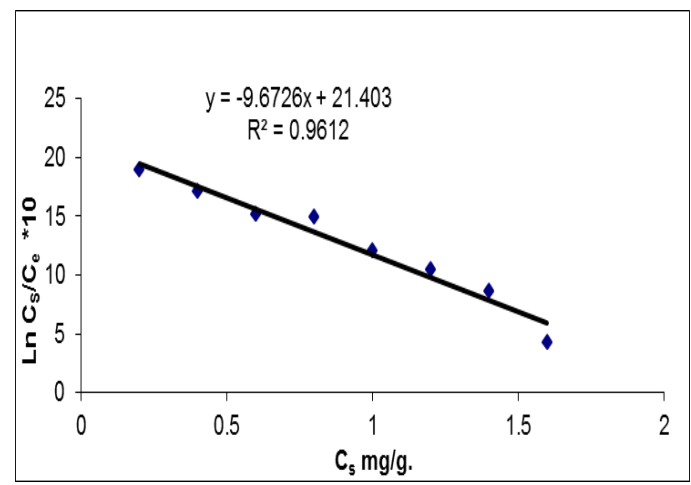

Fig. (13c): Vant Hoof's plotting of MB dye adsorption (200ppm) on MFA copolymer at $318 \mathrm{~K}$

\section{Conclusion:}

Methylene blue dye is one of the most -used material in may industrial, it is toxic and carcinogenic to human and a aquatic life. Therefore, the effluents should be treated prior to discharge, adsorption is others models involving Langmuir, Freundlich, Temkin and $1^{\text {st }}$ , $2^{\text {nd }}$ order kinetic were applied to reveals the $\mathrm{k}_{1}, \mathrm{k}_{2}$, number of adsorbed site on the new copolymer (melamineformaldehyde-p-methoxy-toluene ), the results of kinetic and thermodynamic study support the endothermic homogenous process, since the value of $\mathrm{q}_{\mathrm{e}}=59 \mathrm{mg} / \mathrm{lit}$ of adsorbed $\mathrm{MB}$ dye on MFA it is clear compared to value of $\mathrm{k}_{1}$. Further, this process with its kinetic study satisfies good optimization physic chemical parameters to improve green and lyrical method for purification.

\section{References:}

1. Gulanz O., K. A., M. F. and Arikan.B. 2004."Sorption of basic dyes from aqueous solution by activated sluge" Journal of Hazardous Materials. 108: 183.

2. Tsai W.T., C. C.Y., L. M.C., C. S.F., S. H.F. and Hsieh M.F. 2001. "Removal of anionic dyes from aqueous solution using poly [Nvinyl pyrrolidone/2(methacryloyoxy ethyl) trimethyl ammonium chloride] super welling hydrolysis" J. Chemosphere. 45: 51.

3. Blanca E. and Barragan C. M.M.2007."Equilibrium and thermodynamic studies on removal and recovery of safranine- $\mathrm{T}$ dye from industrial effluents" Carmen, Journal Dyes and Pigments. 75: 73.

4. Ansari R. and Delavar A.F.2009."Application of poly 3methylthiophene for removal of silver ion from aqueous solutions"Jouranal of Applied Polymer Science. 113: 2293.

5. Langmuier I.1918."Langmuir isotherm in relation to mobility and molecular size of the adsorption" J. Am. Chem. Soc. 40: 1361.

6. Freundlich U.1906."Adsorption of some cationic and anionic dyes on magnetite nano particales-modified activated carbon from aqueous solutions: Equilibrium and kinetic stydy" Phys. Chem. 57: 385.

7. Hasany S.M., S. and Ahmed M.2002."Molecular mechanisms underlying morphological effects of protein kinas $\mathrm{C}$ under normal conditions and cellular stress"J. Radiation.Nucl. Chem. 252: 477.

8. Ahalya N., K. R.D. and Ramachandra T.V.2005."The removal and kinetic study of $\mathrm{Mn}$, $\mathrm{Fe}, \mathrm{Ni}$ and $\mathrm{Cu}$ ions from wastewater on to activated carbon from coconut shells" Electron.J. Biotechnol. 8: 25.

9. Tan A.W., A. A.L. and Htion B .2008. "Basic dye using activated 
carbon prepared from oil palm shell: Batch and fixed bed studies "Desalination. 225(1-3): 13-28.

10. Saniz D. and Griffiths A.2000. "Activated carbon from solid wastes using a pilote scale batch flaming pyro-lyser" Environmental Science and Pollution Research. 79( 15): 1863-1871.

11. Weng C.H., L.Y.T and Tzeng T.W.2009. "Removal of methylene blue from aqueous solution by adsorption to pineapple leaf powder" Journal of Hazardous Materials. 170(1): 417-424.

12. Allen S.J., M. G. and Diffusion Y.H.1989. "Basic dye during adsorption on to sphag-num peat" Environ. Pollution J. 56, (1): 39-50.

13. Jadhav D.N and Vanjara A.K.2004. "A study: Removal of dyes tuff effluent using sawdust, polymerized sawdust and sawdust carbon- $\Pi$ " Indian.Chem.Technol. J. 11 (1):4250.

14. Prasad M. and Saxsena S.2004. "Sorption divalent metal ions on to low-cost mineral adsorbent" Industrial. Eng. Chem. Res. 43(6): 1512-1522.

15. Singru R.N., G. W.B., K. V.A., Z. A.B. and Dontulwar J.R.2010."Bio sorption of a model basic onto pinus brutia ten: Evaluting of equilibrium, kinetic and thermodynamic data" Desalination. 263: 200-210.

16. Mohan J. 2001."Organic Spectroscopy Principles and Application" Naro. Pub. Hoa. Delhi. p.267.

17. Macedo ID., S. V.C., A.N.K. and Mishra Im. 2005. "Uncertainty assessment of spatial patterns of soil organic carbon density using sequential indicator simulation, a case study of Hebei province, China" Chemosphere. 61:492-501.

18. Park D. and Jamey W. 1999."Anaerobic- anoxic aerobic sequential degradation of synthetic wastewaters" Applied Biochemistry and Biotechnology.40:115.

19. Ansari R. and Mosayebzadeh Z.2010."Biosorptive removal of cationic dye from aqueous system: A response surface methodological approach" J.Iranian.Chem. 7 (2):334-350.

20. Vasu.A.E. E.2012. "Adsorption removal of tartrazine and methylene blue from wastewater using melamine- formaldehyde- tartaric acid resin and discussion pseudo second order model" J. chemistry.5:844.

21. Robison T., M. G.,Mc.,M. R. and Nigon P.2001."Thermodynamic and kinetic parameters of adsorption study of organic and methylene blue dyes on activated charcoal" Journal. Biosen. Technol. 77:247.

22. Bajpai S.K. and Jain. A.2010 " Sorptive removal of crystal violet from aqueous solution using spent tea leaves: Part I optimization of sorption condition and kinetic studies"Acta Chemica Slovinia. 57: 751-757.

23. Bajpai S.K. and Shrivastava. S.2011." Sorptive removal of methylene blue from aqueous solution by polymer activated charcoal composites" J. Applied. Polymer. Sci. 119(5): 2525-2532.

24. Freundlich H.M.Füber. 1906. "Inductively couples plasma emission study in studying the adsorption some heavy metal ions on methylene blue dyes" Phys. Chem. 57: 385-470.

25. Hamdaoui O. and Chiha M.2007." Removal of methylene blue from aqueous solutions by wheat bran"Acta Chimica Slovinia. 54:407-418.

26. Bajipai S.K., N C. and Manika M.2012."Removal of toxicity some pigments from water via coupling organic reactions" Journal of 
Environmental Sciences. 2(3) :1669-1624.

27. Yaruz E., B., A. H. and Hekmat .2010. " Removal of methylene blue dye from waste water by adsorption in to semi-impetrating polymer network hydro gel composed of acryl amide and acrylic acid copolymer and vinyl alcohol " Iranian. J. Env. Sci. 7(5):431-436.

28. Yao Y., X. F., C. M. and Zhu Z. 2010. "Adsorption behavior of

methylene blue dye on carbon nano tubes" Bioresourse Technology. 101:3040-3046.

29. Taha M. Elmasi .2011. "Equilibrium isotherm and kinetic studies of removal methylene blue dye by adsorption on to miswak leaves as natural adsorption" Environmental. J. Protection. 2: 817-827.

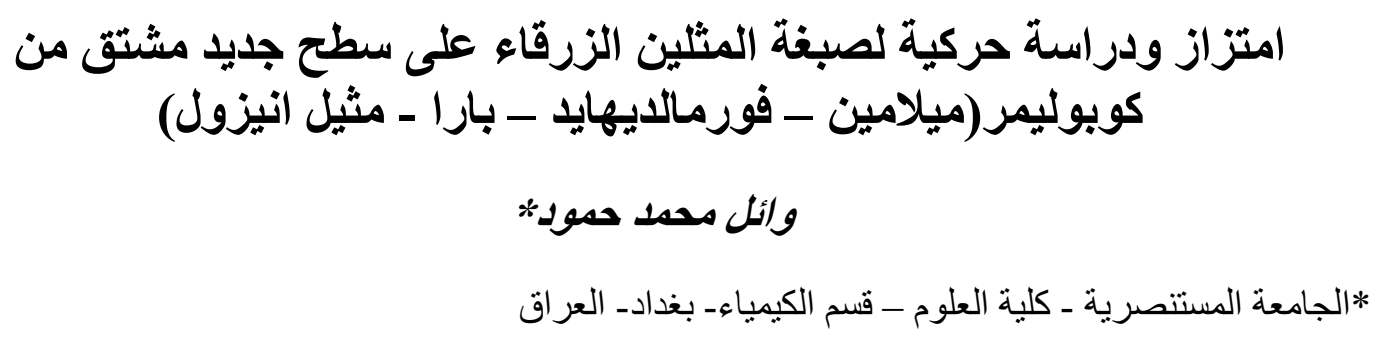

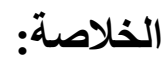

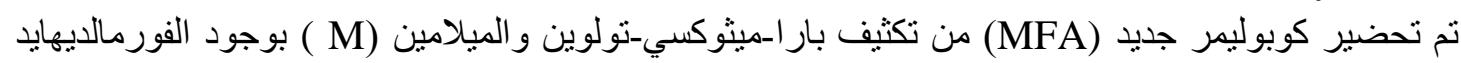

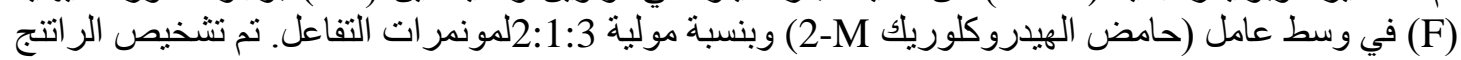

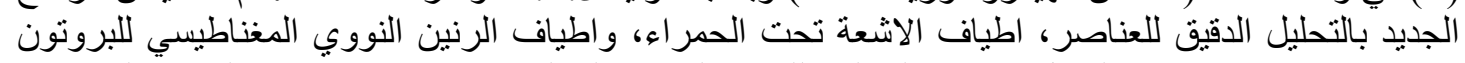
HNMR

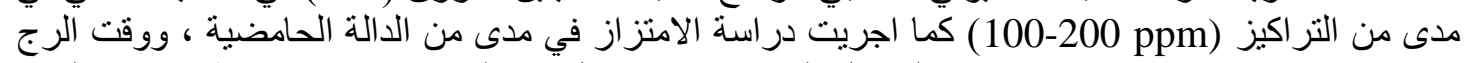

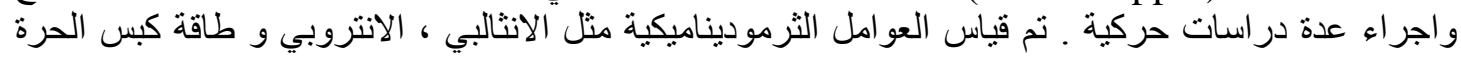

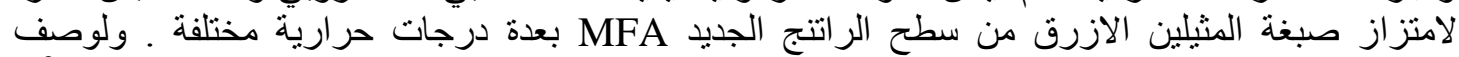

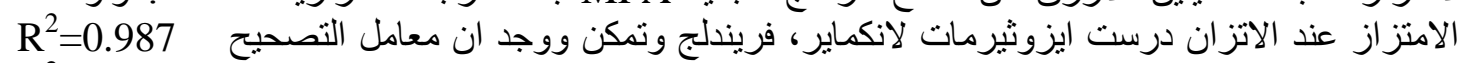

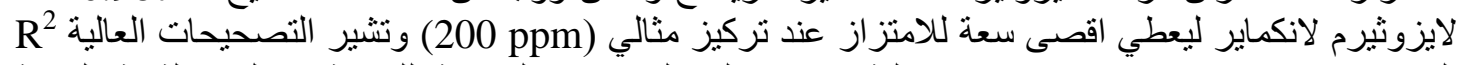

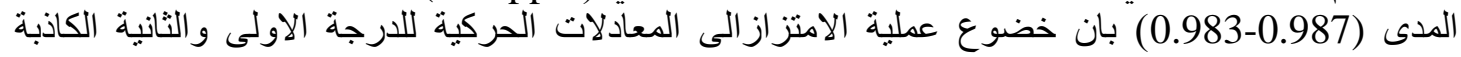

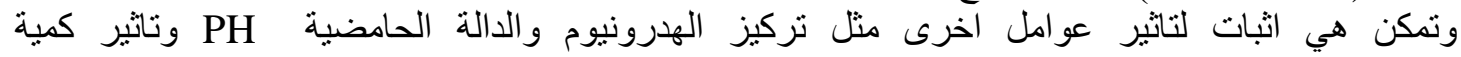

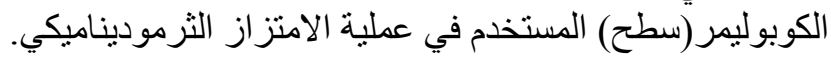

